\title{
ASIA AND OCEANIA CONGRESS OF ENDOCRINOLOGY
}

$\mathrm{T}$ HE second Asia and Oceania Congress of Endocrinology was held in Sydney during May 28-June 3 under the auspices of the Endocrine Society of Australia. The president of the Congress was Prof. C. W. Emmens, and Prof. T. Miyake (Japan), Dr. H. D. Purves (New Zealand) and Prof. V. M. Trikojus (Australia) as vice-presidents.

One hundred and eighty delegates participated in the Congress, including fifteen from Japan, six from New Zealand, five from the Philippines, four from both Great Britain and the United States, two from India, one from Hong Kong and one from Italy. Eighty papers were read from 120 offered.

Prof. A. S. Parkes (Physiological Laboratory, Cambridge) opened a symposium on "Regulation of Fertility", and discussed climatic, social and nutritional factors. Rapid-acting and neural effects were differentiated from the slower-acting responses mediated via the anterior pituitary. The importance of smell as an exteroceptive factor working through slowly acting neurohumoral mechanisms was discussed. Related papers, including a number from workers in Japan and from a group in Sydney on various aspects of ostrogenic and anti-œstrogenic effects, followed the opening paper.

Dr. H. D. Purves (Endocrinology Research Department, Medical Research Council of New Zealand) opened a symposium on "Control of Thyroid Secrotion" and discussed aspects of the feed-back mechanism in relation to control of thyroid function. He was followed by Prof. T. Miyake (Kyoto, Japan), who reported on clinical studies of thyroid hormone metabolism, and a series of papers from groups working in New Zealand, in Melbourne and in Adelaide were presented.

A symposium on "Hormonal Response to Environment" was led by Prof. E. C. Amoroso (Royal Veterinary College, London), who spoke on "The Endocrine Environment of the Foetus" and discussed aspects of the complicated hormonal environment in which the developing mammalian organism grows pre-natally. This was followed by papers from a group in Melbourne on electrolyte balance in ruminants, and by a paper on the suckling stimulus in marsupials from workers in Canberra, and by two papers from Indian workers.

Dr. M. S. Raben (Boston, United States) opened a symposium on "Protein Hormones in Growth", and re. ported investigations of metabolic and clinical effects of human growth hormone. Problems concerned with the production of a satisfactory preparation were summarized and details given of metabolic work on selected patientf receiving these preparations. The characterization os pituitary growth hormones from various species was described by a group working in Sydney.

In addition to these symposia a number of papers on adrenal physiology, comparative endocrinology, steroid hormones and hormone assay were presented in concurrent sessions.

The interest and prominence of a session on hormone assay, particularly of steroid hormones, indicated the concern of many endocrinologists with details of basic methods which will enable reliable results to be obtained by workers in different laboratories and thus lead to comparisons which have some significance.

On the final day a group of papers on clinical endocrinology was presented, and during the afternoon a plenary session was held with The Royal Australasian College of Physicians, which was celebrating its Jubilee in the week following the Congress. The session was opened by Dr. R. F. Escamilla (San Fransisco), who spoke on "Stimulation of Growth in Short Children: Experiments with Human Growth Hormone", and papers were presented from the United States, Japan, India and Australia on various clinical aspects of human growth hormone, anabolic steroids, idiopathic hirsutism, corticosteroid treatment and diabetes in pregnancy.

It is apparent from the general interest of the participants and the quality of the papers presented that the study of endocrinology is being actively pursued in a number of centres in the Asia and Oceania region, and that a high standard is being maintained.

A factor in the success of the Congress was associated with the opportunities afforded delegates to make new, and renew old, acquaintances. The site of the Congress, a section of the Chemistry School, University of Sydney, and the limited number attending were both conducive to a free circulation of members during lunch and tea periods. The spirit of informality pervaded the lecture rooms and led to that most important aspect in the success of a Congress, lively and friendly discussion.

Acknowledgement should be made to the Executive Committee for their organization and to Dr. P. J. Claringbold (C.S.I.R.O. Division of Animal Genetics), the secretary to the Congress, for his excellent administration, which contributed largely to its success.

The third congress will be held in Manila in January 1967.

I. G. JARRETT

\section{VOLTA BASIN RESEARCH PROJECT}

\author{
By Prof. G. W. LAWSON \\ Department of Botany, University of Ghana, Legon
}

$\mathrm{W}$ HEN the Volta Dam in Ghana is completed next year a lake will begin to form which will eventually cover an area of 3,275 square miles. This will be the largest man-made stretch of water in the world. The water-level will begin to rise in about September after the rainy season of 1964 and will reach the $200-\mathrm{ft}$. contour in the first year, but the final level will not be reached until some years later. The Volta Scheme will primarily provide hydro-electric power for an aluminium smelter at the new port of Tema which will ultimately produce 120,000 long tons of aluminium per annum, mostly for export. Ghana is and has always been an agricultural country relying mainly on the export of cocoa for the foreign exchange needed to buy manufactured goods. The availability for the first time of cheap electricity means that conditions will be created for a rapid industrial revolution with an inevitable rise in standards of living throughout the country.

Additional benefits from the scheme will include a large freshwater fishery and a cheap inland water transport system. It is also planned to grow crops, especially rice and sugar cane under irrigation. Undoubtedly the impact on Ghana's economic life will be tremendous.

The creation of the lake will also, however, have many important biological implications, the most important and immediate of these being the removal and rehabilitation of more than 70,000 people from the area to be flooded. This work is being undertaken by the Volta 
River Authority, a Government body set up to control all aspects of this far-reaching scheme. The transplantation of these people, consisting of many different tribal, language and religious groups, and about who there exists little written information, creates far-reaching sociological problems.

As with every major development project, it is necessary, by careful advance study and planning, to safeguard against certain dangers which so large a change in the environment is capable of provoking. One such danger, in this case, is that certain water-borne diseases such as bilharzia and onchocerciasis (river blindness), already serious in Ghana, will become accentuated. There is also the undoubted possibility that aquatic weeds may become a serious problem as they did at Kariba Lake in Central Africa, where more than 200 square miles of water is covered by a dense mat of Salvinia auriculata adversely affecting fisheries and making lake transport difficult or impossible.

Apart from these intensely practical problems many more academic but highly interesting phenomena require investigation. A biological and physical survey needs to be undertaken now to ascertain the populations of fish and other animals that at present inhabit the Volta River and its tributaries and the conditions under which they exist. Likewise the phytoplankton will undergo a unique series of changes as the lake forms. On the human side there is much information to be gained about such subjects as the distribution of language groups and the social organization of the inhabitants of the Volta Basin area before they are moved. Several archæological sites need to be investigated. They do not compare in importance, of course, with the monuments in the Sudan which may be lost by the building of the high Aswan Dam, but in view of the relatively little that is known of the pre-history of West Africa they are of distinct academic interest.

Not only the Basin area but the area below the Dam will be affected both biologically and economically. The present seasonal flooding enriches both the land used for agriculture and the numerous creeks used for fishing by the riverine population. During the dry season, when the river is low, collection of river clams (Egeria radiata) is carried out. This flourishing industry, which employs several thousand women and is worth about $£ 100,000$ a year, will be threatened by the eventual steady flow which will be too fast throughout the year for collection to take place and which may also affect the delicate balance of saline and fresh water in which the clams thrive. Transplanting of the clams to more favourable areas may be possible. Such problems must be investigated and possible solutions to them need to be attempted before it is too late.

These are just some of the things that cry out to be done in the little more than a year that remains before flooding, and in view of the urgency that exists the University of Ghana has decided to launch a Volta Basin Research Project. Work by existing staff has already commenced on several aspects of research connected with the project and it is intended to recruit Research Fellows to undertake specific problems. The Project Committeo will welcome any outside assistance and will endeavour to give every possible help to individuals or groups who wish to be associated with it.

The initial financing of the project is being provided by the University, and the project has the support and approval of the Volta River Authority and the United States A.I.D., who, it is hoped, will be able to contribute to its development both as regards equipment and personnel.

\section{ANALYSIS OF THE LIFE-CYCLE IN MAMMALIAN CELLS}

$\mathrm{U}^{\mathrm{n}}$ NDER this title Defendi and Manson ${ }^{1}$ have recently published results obtained with a few normal and aberrant types of mammalian cells, and from these results, and from a selection of information taken from the literature, they have generalized "that most mammalian cells of normal and tumour origin, in vivo or in vitro, pass a similar period of time in DNA synthesis and in preparing for mitosis irrespective of the generation time". It is possible that this conclusion may ultimately prove to be justified, but at the moment the available evidence scarcely appears to be adequate, and a more appropriate conclusion might be that for most mammalian cells of normal and tumour origin no information exists at all.

They further conclude that "the primum movens of cell division has to be searched for not at the initiation of mitosis but farther back in the cycle at the time of initiation of DNA synthesis". This has, of course, been obvious for a long time, although the important proviso must be added that the actual point at which the cell commits itself to prepare for division may well be earlier than the point of initiation of DNA synthesis. The beginning of DNA synthesis is merely the earliest point that can be observed with present-day techniques.

Finally, they quote the conclusion of Gelfant ${ }^{2}$ that adult mammalian epidermis is an exceptional tissue in that it contains a unique population of cells which have completed DNA synthesis but which remain quiescent for "an indefinite period of time, acting as a reservoir of cells immediately ready to undergo mitosis". Unfortunately, for a variety of reasons Gelfant's conclusions cannot be accepted; it is sufficient to note that his published results are statistically inadequate. However, as is shown here, there may well be a half-truth in this particular conclusion.

In view of the confusion which may be created it seems necessary to set out the most significant of the evidence now available regarding the mitotic cycle in adult mammalian cells. However, before doing this it is necessary to analyse, name and define the phases through which a regularly dividing cell passes (Fig. 1). The literature contains a varied and sometimes contradictory termin. ology.

Cycle of cell growth and mitosis. The generation time is the time taken by a cell to pass through the whole cycle, for example, from prophase to succeding prophase. There is a large literature on the generation times of various tissues and cell types, and this has been well reviewed ${ }^{3,4}$

On present knowledge the whole cycle of cell growth and mitosis can be subdivided as follows:

(1) Early interphase: the period between the end of telophase and the time when the cell 'decides' whether to differentiate or to prepare for yet another mitosis (in the literature this phase is variously called "G 1 ", the "first growth phase", the "first gap", or the "presynthetic resting phase").

(2) Dichophase: a new name derived from $\delta \iota \chi 0$ (expres. sing doubt between two ways ahead) and here used to define what may be the most interesting and important phase in the whole cell cycle, the "phase of decision" when within the cell a 'choice' is made between synthesis leading to differentiation and synthesis leading to division. The duration of this phase is unknown.

(3) Prosphase: a new name derived from $\pi \rho \circ$ (expres. ing movement towards) and here used to define the whole 